\title{
Re-examining the fluctuations in language in-education policies in post-independence Ghana
}

Gladys Nyarko Ansah

\author{
Correspondence: \\ gansah@ug.edu.gh \\ Department of English University of \\ Ghana, Legon, Accra, Ghana
}

\begin{abstract}
Language- in- education policy in Ghana has been in a flux since British colonial rule but particularly so after independence. A close examination of post independence language in education policies shows these fluctuating policies have moved from one form of bilingual education policy to another. Many tensions and paradoxes that arise from bilingual education policies in multi-ethnic/multilingual communities stem from a conflict between policy decisions that are rooted in a particular linguistic tradition and the sociolinguistic realities such policies are to address. In this article, I present a brief historical account of the developments of language policy in education in Ghana since independence and argue that while the flux may have been caused in part by instability in government leadership, it may have also occurred as a result of possible tensions between the set objectives and the implementation of such policies, i.e. that the policies may have been based on assumptions that do not reflect the sociolinguistic practices in Ghana.
\end{abstract}

\section{Introduction}

According to Freeland (2003, p.239), the frequent collocation of the terms multilingualism and bilingual education in the literature suggests 'an image of mosaics of discrete linguistic and cultural groups'. This seems to have been the framework within which early language in education policies operated. They were designed to assimilate minorities, indigenous or immigrant groups into societies that were imagined to be monolingual or mono-cultural. Such language policies aimed at producing people with bilingual competences in their original language and a dominant language or state language. While such language policies have been adopted and applied in multilingual/ multi-ethnic communities, findings from recent research suggest that 'the multilingual, multicultural mosaic itself is ideologically constructed' (Freeland, 2003, p.239).

In other words, the assumption that multilingual/multi-ethnic communities are clearly bounded and homogeneous along linguistic lines is merely ideological. Indeed, ethnographic studies of multilingual practices in research contest such essentialist assumptions (Le Page and Tabouret-Keller, 1985; Rampton, 1995). Such studies on highly multilingual/multicultural communities around the world, e.g. India (Pattanayak, 1990), Africa (Heugh and Pluddeman, 1995), Pacific (Mühlhäsler, 1996), and Central America (Freeland, 2003), have demonstrated the inadequacy of relying on essentialist 
assumptions about communities for language policy and planning in complex multilingual societies where people have fluid multilingual identities. Indeed, researchers on ideologies of language, for example, Blommaert $(1996,1999)$, have related such essentialist assumptions to European traditions of nation building. Generally, essentialism may be defined as the belief that people or phenomena have an underlying and unchanging essence (characteristic). In this article, essentialist assumptions refer to the belief that within a multi-ethnic community, ethnic groups together with their languages and cultures are clearly bounded and internally homogeneous.

Ministries of Education across multi-ethnic/multilingual Africa, e.g. Kenya (Hemphill 1974), South Africa (The Bantu Education Act 1957 and National Education Policy Act act no. 27 of 1996), have experimented with bilingual education policies that encouraged mother tongue education. Ghana is no exception. Ghana has tried to implement several versions of bilingual education policies since independence without achieving the desired results. Why have these policies failed to achieve the desired results? This article provides a brief overview of the current linguistic landscape in Ghana and a brief history of the development of language policies in education in Ghana. The article then explores possible explanations why language in education policies in Ghana have failed to achieve the desired results. This is done by linking the policies to possible theoretical underpinnings that make wrong assumptions about language realities in multi-ethnic/ multilingual communities.

\section{The linguistic situation in Ghana}

Accoding to 'ethnologue ${ }^{a}$, there are 79 languages (belonging to the Proto Tano, VoltaCongo language groups) in Ghana (Lewis, 2009). These languages are distributed over a speaker population of approximately 24 million people spread over ten geographic/ administrative regions (Ghana Statistical Services, 2002). These languages tend to be closely associated with ethnic groups. Subsequently, one may easily assume that there are as many ethnic groups as there are languages in Ghana. However, a close examination reveals that what is usually described as a language group typically consists of a cluster of socio-culturally and linguistically related ethnic groups who do not see themselves as internally homogeneous. For example, Akan, the largest ethnolinguistic group in Ghana, is constituted by a cluster of ethnic and sub-ethnic groups who speak different but largely mutually intelligible dialects of the Akan language. According to the 2000 population studies figures (Ghana Statistical Services, 2002), the Akan ethnic group alone constitutes $49.1 \%$ of the national population; Mole-Dagbani16.5\%; Ewe 12.7\%; Ga-Adangbe 8\%, and Guan 4.4\%. (See Figure 1 below).

From the chart above, it is obvious that there are unequal levels of vitality for each of the 83 languages. For instance, while $90.7 \%$ of Ghana's population is constituted by only 5 ethnic language groups, the remaining 78 ethnolinguistic groups constitute only $9.3 \%$ of Ghana's population. Again, from the chart, it is obvious that Akan is the largest ethno-linguistic group in Ghana.

In addition to these indigenous languages, other languages are spoken in Ghana for various reasons. For instance, Hausa, a West-African trade language, originally from northern Nigeria, is widely spoken in Ghana to the extent of being used in national radio and television broadcasting by the Ghana Broadcasting Corporation, the only 


\section{Ethnic distribution in Ghana}

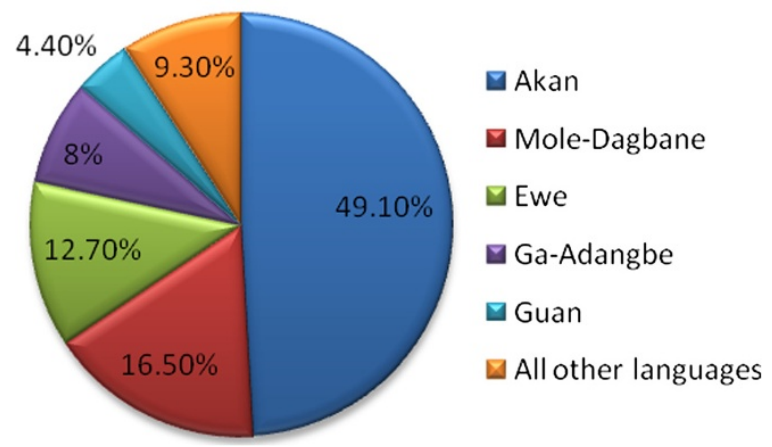

Figure 1 Ethnic distribution in Ghana- Ghana Statistical Services 2002.

government-owned radio and television station, and the only broadcasting station with a nation-wide coverage. This is because Ghana is a member of the Economic Community of West African States (ECOWAS), which encourages free movement and trade within member countries. Ghana shares borders with three francophone countries - Togo to the east, Cote d'Ivoire to the west and Burkina Faso to the north. The existence of strong trade and social (marriage) relations between Ghana and these countries, especially among the people who live along the borders as well as official legislation to include the study of French in basic education have resulted in the acquisition of different levels of proficiency in French among a section of the Ghanaian population. Finally, English, a colonial legacy, is the official language in Ghana, the prescribed language for all formal and official communication. In short, Ghana is a highly multilingual country with no national language. As a result, language choice in national but non-formal contexts is determined by social factors, such as the background of the interlocutors involved in the communication. However, English, Akan and Hausa have emerged as important lingua francas and forms of diglossia have developed in Ghana (Obeng, 1997). See Figures 2 and 3 below for the administrative map and the linguistic map (the regional/geographic distribution of the languages in Ghana.

\section{The development of language- in- education policy in Ghana}

According to Agbedor (1994), the earliest form of formal (Western) education in Ghana is recorded as starting with the castle schools in the 15th Century. These were schools that were established by the European settlers at their forts (The Christianborg Castle Accra (Danish), Elmina Castle (Portuguese then Dutch) and the Cape Coast Castle (British) to provide education to children and relatives of wealthy African merchants, children and relatives of some important chiefs but largely Molato children of European castle staff by African women. These schools were not meant for the formal education of indigenous Ghanaian pupils. During this era, there was no official language- in- education policy; the medium of instruction in the castle schools shifted from one European language to another depending on which European group was in control at the time. During the mission school era (1529-1925) however, the various missions had and practised different private language policies in education. For instance, while the 


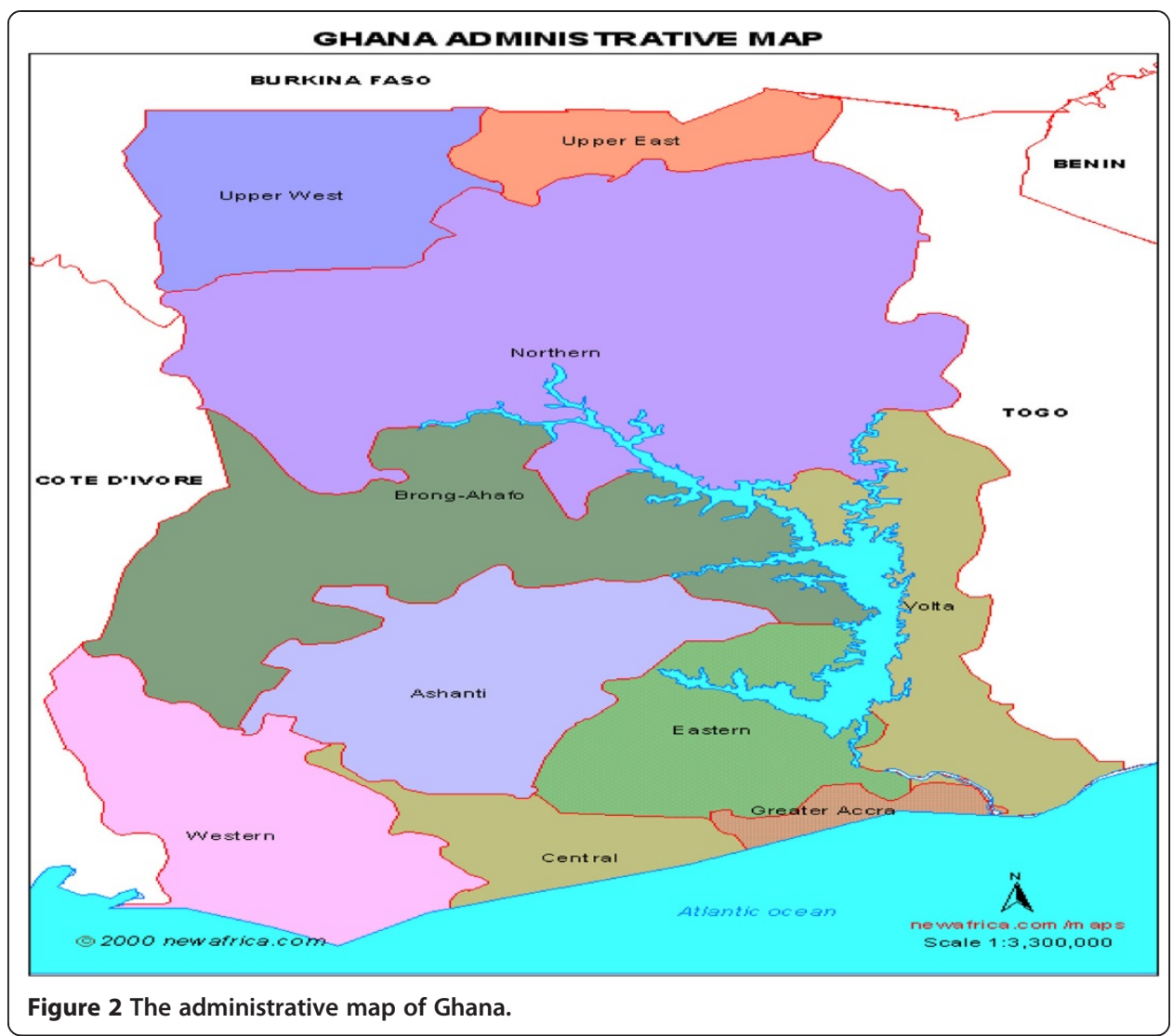

Wesleyan Mission emphasized the use of English language, the Basel and Breman missions encouraged the use of the local/indigenous Ghanaian language in the areas where they operated. In other words, while the Wesleyan mission adopted an English monolingual education policy, the Basel and Breman missions adopted a mother tongue based education policy, using the native languages of the localities in which they operated as the medium of instruction in formal education (Agbedor, 1994).

Since there were more missionary schools that operated a mother tongue-based education policy than any other kind of school at the time, the use of Ghanaian languages in education was so deeply entrenched that in spite of the fact that it was a private policy (the missionary societies had been operating as independent groups) when the colonial government took over the administration of education in Ghana in 1925, it could not reverse the mother tongue education policy (Bamgbose, 2000). While British colonial governments tried to centralise education in Ghana by passing, trying and abandoning several education ordinances, there was no official language- in- education policy until the reign of Sir Gordon Guggisberg (1919-1927) when the first official language- in- education policy was legislated in 1925. The first language -in- education policy was a bilingual (mother tongue and English) policy that made the use of mother tongue as the medium of instruction at lower primary school compulsory (Agbedor, 1994, p.149). 


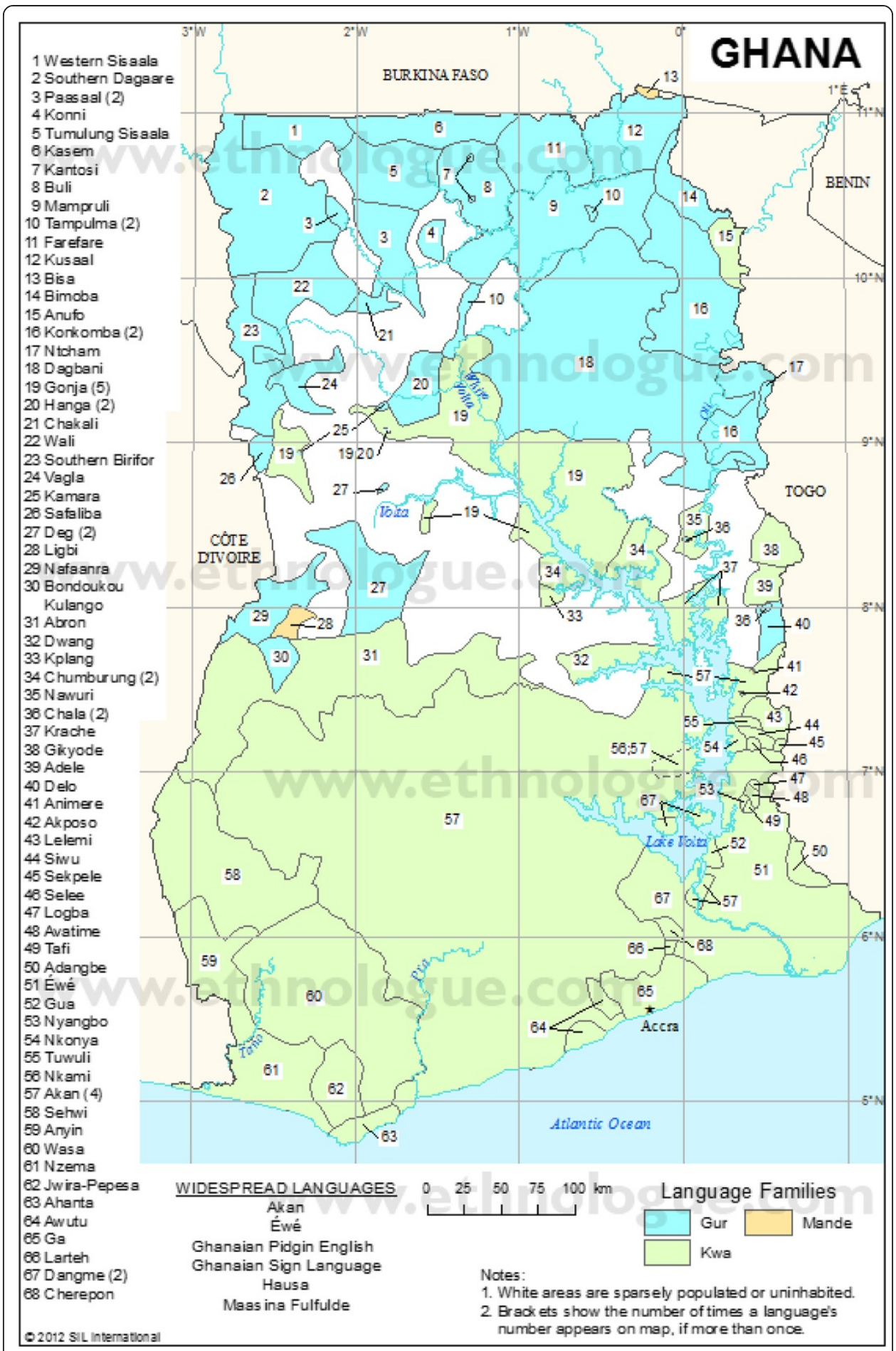

Figure 3 The language map of Ghana - Ethnologue 2013.

In 1927, the Guggisberg Education Committee, set to review the government's education policy, made the following recommendations with regards to language- in- education policy:

i. That in line with Guggisberg's idea that the children of Ghana must not be denationalized; vernacular should be used as the medium of instruction at lower 
primary school. However, English was to be introduced as a subject of instruction in early primary;

ii. That, in line with the Basel mission policy, text books in vernacular should be produced. English, which was to be taught as a subject at lower primary, then replaced mother tongue as the medium of instruction from primary four onwards while indigenous Ghanaian languages were to be studied as subjects. (Agbedor, 1994, p.149)

The encouragement of the vernacular in education was interpreted by the people of Ghana as a somewhat deliberate attempt by the British government to provide inferior education to the Africans, perhaps because of the negative connotations, (e.g. nonstandard, non-literary and not cultured) that were typically associated with the term 'vernaccular'. Hence, under the Government's 'Accelerated Development Plan' of 1951, the three year mother tongue education policy was changed to early mother tongue medium policy (1951-1956), which made the child's mother tongue the medium of instruction at primary one only, and then replacing it with English thereafter. On the eve of independence in 1956, 'The Bernard Committee' was set up to investigate the feasibility of the use of English as the sole medium of instruction in formal education in Ghana. The Committee recommended a return to the 1951 three year mother tongue education policy. Even though the committee's report was accepted by government, a member of the committee submitted a minority report recommending an English only policy.

The post independence policies have been the most fluctuating. The first Ghanaian administration after independence (1957-1966) adopted the minority report of The Bernard Committee of 1956, which recommended an English only policy. However, with the overthrow of the first post independence government in 1966, the military government that took over between1967-1969 reverted to the 1951 early mother tongue medium of instruction policy (L1 at primary one only). The restoration of civilian rule in 1970 saw another change in the language policy in education. From 1970 to 1974, Ghana reverted to the 1925-1951 three-year mother tongue education policy. However, the 1970-1973 policy had an additional dimension, i.e. the learning of a second Ghanaian language in addition to the child's own L1. Four Ghanaian languages, namely, Akan, Ewe, $\mathrm{Ga}$, and Nzema were selected as the additional Ghanaian languages to be learnt (Agbedor, 1994). Another interesting aspect of the 1970-1973 policy was that even though the civilian government that introduced it in 1970 was toppled by a military regime in 1972, the military regime did not change the policy. It only added another dimension - the introduction of French into primary school curriculum to promote regional communication with the neighbouring Francophone countries.

In 1974, the existing language policy was slightly modified. While maintaining the three year mother tongue education policy, the mother tongue/Ghanaian language, in this instance, was defined as any of nine selected 'languages of the locality'. The selected languages were: Akan (Fante and Twi), Nzema, Ga, Ga -Adangbe, Ewe, Gonja, Kasem, Dagbani, and Dagaare (Owu-Ewie et al. 2006, p.77). The assumption here was that at least one of these nine languages was commonly spoken in every locality within the country. This policy is the longest surviving language policy in education in Ghana. Even though there were a few more changes in political administration in Ghana within 
that period, no substantial change was made to this language policy until 2002. The only significant modification to the 1974-2002 policy occurred with the introduction of Ghana's educational reforms in 1987, which made the study of a Ghanaian language a compulsory subject up to secondary school level. The previous policies had made the study of a Ghanaian language a compulsory subject up to primary six only.

In 2002, this longest lasting language policy in education since independence was once again changed when the then New Patriotic Party (NPP) government introduced an English-only policy while making room for a Ghanaian language to be studied as a compulsory subject up to the Senior Secondary (Senior High) School. According to the then minister of education, Professor Ameyaw-Akumfi (2002), the government's decision was informed by the realisation that among other things, the previous policy was abused by some schools, especially, in rural Ghana, where some teachers never used English in the classroom throughout primary school education. English was taught only as a subject, but never became the language of instruction, allegedly resulting in the compromise of competence in the English language.

This incompetence, the minister alleged, was evident in some students' inability to speak and write 'good' English sentences even by the time they complete secondary education. The government's announcement of the introduction of the new policy attracted mixed public reactions. On the one hand, many parents seemed to support the new policy in the face of the fact that every year, a considerable number of basic and secondary school pupils/students fail either in English or several school papers because they are set in English. These students are disqualified from further education or employment, which drains parents' financial resources as they struggle to arrange for private tuition for their children to re-sit the failed papers. On the other hand, the government's announcement of the introduction of an English only language policy in education provoked various criticisms and fierce debate across the Ghanaian population including linguists, educationists, and ordinary people. For example, the then head of the Linguistics Department, University of Ghana, Legon, engaged the then minister of education in a heated debate on national television as to why the government's decision would not benefit the majority of Ghanaian children who were already disadvantaged in many ways. The criticisms against the new language policy were followed by a call on the government to revert the policy, challenging the sense or essence of promoting a monolingual ideology in multilingual classrooms. While the criticisms may be said to have some socio-political undertones, it is a question of Afrocentric/PanAfrican ideology versus an imperialistic one. There are several African scholars who believe that the continuous use of colonial languages, e.g. English, French and Portuguese, as the national language in post colonial African countries is an indication of lack absolute freedom and independence from colonial rule.

For instance, in October 2000, the threat of the then president of Kenya, Daniel Arap Moi, to ban all radio broadcasts in languages other than English or Kiswahili was criticised in very strong terms. According to BBC news (2000), which described the president's move as 'a linguistic genocide', 'an opinion piece in The Nation argued that as well as muzzling freedom of expression a ban on the vernacular would be in direct contradiction to pan-African efforts to rehabilitate African languages and culture in a post colonial era'. Indeed, at the sixth ordinary session of the Assembly of the African Union 2006, the Assembly declared 2006 as the year of African languages. So strong 
were the arguments and criticisms against Ghana's 2002 language policy in education that the NPP government indeed reconsidered its decision and changed it in 2007. The 2007 language -in- education policy is still in use in Ghana.

The current policy, since September 2007, reverts to the 1974-2002 three-year mother tongue education, but with some significant modifications. Among other things, the policy states the following:

i. The medium of instruction in Kindergarten and Lower Primary will be a Ghanaian Language and English, where necessary;

ii. English is the medium of instruction from Primary 4 in the school system. This means that success in education at all levels depends, to a very large extent, on the individual's proficiency in the language (Ministry Of Education Science and Sports, teaching syllabus for English Language, September 2007).

To the average lay person in urban Ghana, the 2002 language policy in education was a proactive measure by the government to solve the apparent problems inherent in the previous policy. The current policy (2007) seems to have taken several factors into consideration. For instance, it includes pre-schoolers in the policy; a step none of the previous policies took. In addition, by making room for the use of English or a Ghanaian language (where possible) as the language of instruction, the current policy provides more opportunity for children to be taught in a familiar language. On the one hand, the few children who speak English as L1 get to be taught in English right from the pre-school stage (four years old). On the other hand, while children who speak Ghanaian languages as L1 may be taught in their L1s or a familiar language, they also get to be familiar with the English language from 4-9 years old, long before English becomes the sole medium of instruction. Nevertheless, the 2002 policy did not solve all the problems. For instance, the problems associated with equating a dominant (community) language with a mother tongue have not been addressed nor is the problem of ensuring that primary school teachers are equipped and able to teach in the languages of the community addressed. Another significant modification in the current policy is the removal of Ghanaian languages as a compulsory and examinable subject at the secondary school level. Issues in language in education policies in multilingual communities - 's experience section below discusses some of the short-comings of these policies. Some suggestions to addressing these short-comings are offered in the concluding section.

\section{Issues in language in education policies in multilingual communities - 's experience}

From the account so far, it is clear that the various planners of language policies in Ghana over the years attempted to take care of the language needs of a multilingual population whose education must necessarily position them to be able to interact not only with people of different ethnic backgrounds in their local community but also with people from outside their local community in a world that is becoming increasingly globalised. More importantly, several of the various language in-education policies discussed above seem to have recognised the importance of mother tongue education to the overall personal and educational development of bilingual children (Cummins, 
2000; Baker, 2000; Skutnabb-Kangas, 2000). These notwithstanding, the policies appeared inadequate in addressing these language needs. In other words, Ghana has struggled (and may be still struggling) to implement language policies in education including bilingual education policies for a multi-ethnic/multilingual population over a period of more than 50 years. What may have caused or may be causing the struggle? Have there been problems with the policies themselves or with their implementation? Focusing on the 1974-2002 policy, the longest lasting language -in- education policy in Ghana, I shall suggest that while bilingual education is necessary in Ghana, the constant fluctuations of language in education policies over the years may be attributable to a failure in the implementation of these policies, which in turn may be attributable to the fact that the policies may have been inadequate in addressing the sociolinguistic realities of a highly multi-ethnic community where people have fluid multilingual identities rather than a mosaic of ethno-linguistic identities.

\section{Making essentialists assumptions about/multicultural communities}

According to Freeland (2003), very often the asymmetrical relations that exist between ethnic groups within multi-ethnic communities are reflected and reproduced through language. She, however, warns against using such asymmetrical relations as the basis for language policy and language planning, including language- in- education policy. This is because any language policy that is based on such relations will be inherently modeling essentialist assumptions about multilingual/multi-ethnic communities, which treat ethnic groups and cultures (with their languages) as clearly bounded and internally homogeneous. Indeed, recent research on highly multilingual/multicultural communities, e.g. Nicaragua (Freeland, 2003) has shown that models of bilingual education that are based on such essentialists assumptions about multilingualism/multiculturalism are inadequate for language planning and language- in- education policy in 'complex multilingual societies.

For instance, the 1974-2002 language policy in education espoused the benefits of mother tongue education in Ghana. However, the policy appeared inherently problematic. The first major problem was identifying the child's mother tongue in certain instances within such linguistically heterogeneous contexts. Jespersen (1922) position on defining the mother tongue is that the child's mother tongue refers to the initial language in which the child learns to communicate with peers and caregivers from early years:

The expression 'mother tongue' should not be understood too literally; the language which the child acquires naturally is not, or not always his mother's language ... but of those with whom the child comes into closest contact from the age of 3 or so, thus frequently servants but even more effectually playfellows of his own age or rather slightly older than himself... (Jespersen, 1922, pp.146-147).

However straightforward this definition may appear, it may not be entirely applicable in all linguistic contexts. In fact, recent research suggests that defining mother tongue in complex multilingual contexts is not a straightforward thing at all (Sebba, 2000). For instance, what is the mother tongue of a Ghanaian child of Ewe-speaking parentage, who lives in an Akan speaking community in Accra but attends an English only medium 
private school in a predominantly Ga-speaking neighbourhood, and speaks all four languages fluently from an early age? Indeed, some researchers, for example, Le Page and Tabouret-Keller (1985), Skutnabb-Kangas (1981), and Pattanayak (1981) contend that in multilingual communities, it is possible to find people with more than one mother tongue.

This is the case for several children in Ghana. Thus, identifying the child's mother tongue or even determining which of the child's mother tongues should be used as a medium of instruction in education in Ghana could be problematic. In an on-going study by the current writer, 56 native Akan-English bilinguals of adult population were selected from urban Ghana to participate in focus group discussions. The analysis of the demographic information compiled on the participants reveals that $58.8 \%$ of the 56 participants indicated that they ethnically belonged to a Twi dialect of Akan, 19.7\% were Fante while 10.7 were ethnic Bono. The remaining $10.7 \%$ said they were not ethnic Akans at all even though they indicated they were native speakers of Akan. However, $78 \%$ of the participants indicated the Twi dialect of Akan as their first language, Fante 7\%, Bono 2\%, English 2\%, English and Akan 9\% and others 2\% showing that participants' ethnic identities do not neatly correspond to their linguistic identities. Figures 4 and 5 below show ethnic group and first language distribution of the 56 native Akan participants respectively:

Figures 4 and 5 above show clearly that identifying or determining the mother tongue or first language of a child may be an extremely complex task, especially in multi-ethnic/ multilingual communities where one's mother tongue does not necessarily correspond to the language of their ethnic origin. Thus, any language in education policies that are based on assumptions that simply equate a child's mother tongue to the language of the child's ethnic origin in complex multi-ethnic/multilingual communities may fail to achieve their objectives.

\section{The dominant group argument in language planning and language policy}

Another shortcoming of the 1974-2002 language policy in education in Ghana is the selection of only 9 out of over 80 indigenous languages as representative languages of various 'localities'. This is because assuming that all the languages have native speakers,

\section{Ethnic Origin}

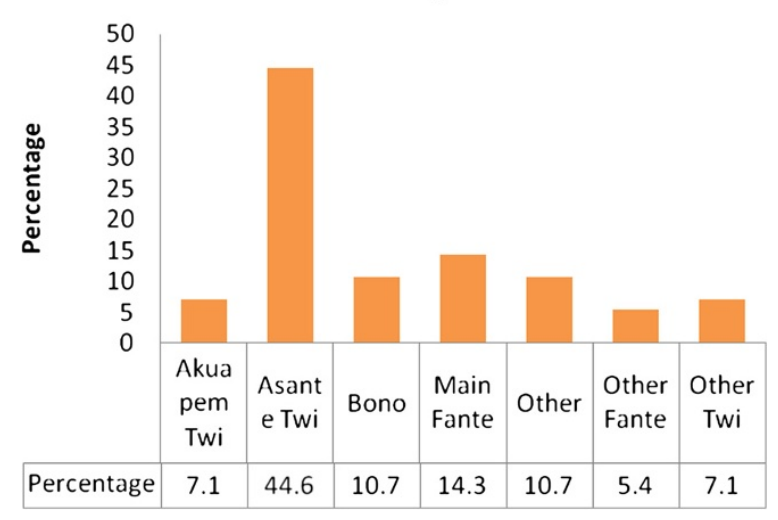

Figure 4 The distribution of ethnic origin of 56 Akan-English bilinguals in Ghana. 


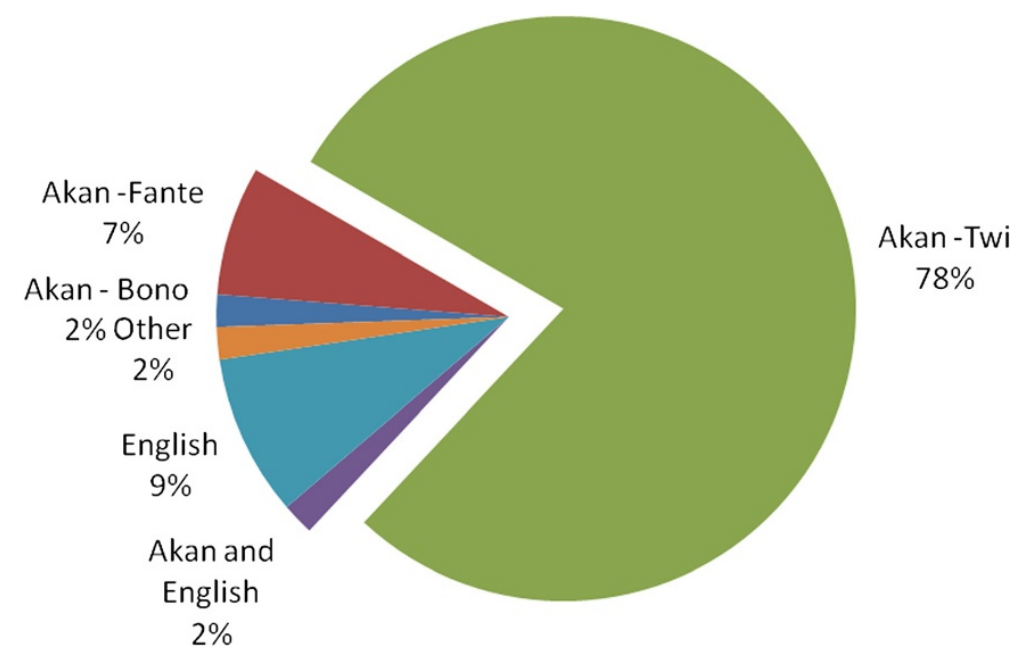

Figure 5 The distribution of first language of 56 Akan-English bilinguals in Ghana.

including school-going children, the policy deprived several children of the benefits of mother tongue education it sought to achieve. Indeed, the lack of a clear definition of which language constituted the 'language of a particular locality' was even more problematic. Was it the native language of the child, its parents or was it the ethnic language of a given geographic/administrative region whether it was the dominant language of that area or not? The policy seemed to have assumed, at least that was how it was interpreted, that children living in a particular geographic region (locality) where a particular Ghanaian language is widely spoken automatically acquire that language as a mother tongue. In effect, what this policy said was that irrespective of the child's mother tongue, the language of education was to be the dominant language in the locality where the child went to school irrespective of whether the child was positioned to receive instruction in that language or not.

Even then, the concepts of a dominant language and locality are very fuzzy. What were the boundaries of a particular locality, and what counted as a dominant language? For instance, under the 1974-2002 policy, the implementers decided only Akuapim Twi would be used as the medium of instruction for schools in Akan-speaking towns of the Eastern region. Children were therefore required to be able to at least read and write Akuapem Twi as it would be the expected language of examination at the lower primary. The problem is that for many of the Akyem, Kwahu and Asante speaking children in the Eastern region, Akuapem Twi was neither their mother tongue nor a dominant language. Thus, inherently, this policy was discriminatory, forcing children from minority language backgrounds living in majority language localities or children from an otherwise dominant language that is not supported by official legislation to adopt another language, dominant or not, as their mother tongue. For instance, as per this policy, Ga-speaking children whose parents are transferred to an Nzema- speaking community would be made to receive formal education in Nzema whether they understood it or not.

This language policy invariably made many Ghanaian children bilingual in other Ghanaian languages, as children whose mother tongues were not used as the language of education in the first three years of formal education had to learn one or more of 
the so called 'languages of the locality' in order to receive formal education. In other words, even though the letter of the policy espoused mother tongue education, the spirit of the policy encouraged mother tongue education for children from local majority language groups and second language education for children from minority language groups.

The selection of the nine 'languages of the locality' made the policy practically non implementable in another sense. Granted that materials for teaching all subjects from P1-P3 (except English) were prepared in all 9 selected Ghanaian languages of the locality (which may not have been the case), the policy implementers had to ensure, in addition, that every teacher posted to a particular locality could not only speak the language of the locality, but was competent enough in it to teach all subjects, including modern science and mathematics. For obvious reasons, this was not or could not be done. Both the teaching syllabuses and teaching materials for primary schools, apart from text books on Ghanaian languages as subjects, are always in English. This means that the teachers had to translate the lessons from English to the language of the locality. In effect, the policy potentially made teachers who neither had the knowledge of the language of the locality, nor the competence, unprepared to teach in the classrooms.

Unfortunately, this is the situation. Since there is no legislation (or any special effort) in Ghana that ties a teacher's work location to the Ghanaian language(s) he/she speaks. There are teachers who do not speak the dominant languages in the locality where they teach. Indeed, in a national survey that was meant to inform school language policy decisions in Ghana, Andoh-Kumi (1999) reports of instances where P1-P3 teachers indicated that they did not speak the local language in which they were required to teach the children in. Thus, the policy's inherent assumption that every teacher could speak the dominant language in the geographic region where they taught was wrong.

\section{The sociolinguistic realities of highly linguistically diverse communities in Ghana}

Again, this language policy discussed in 3.2 could not deal with Ghana's urban population which is linguistically very diverse. For instance, the native language of the indigenous people in the capital city, Accra, is Ga. However, Ga is not the most widely spoken language in several parts of Accra. With a rather high rate of rural urban drift, large groups of native speakers of other Ghanaian languages have settled in Accra, the most urbanized city in Ghana. While there are areas in Accra where one can clearly identify a particular language as dominant, e.g. Nima -Hausa, Ga and Ewe; Chokor-Ga, Avenor-Ewe, Abeka- Twi/Akan, there are many other areas where the population is so mixed it is difficult to identify a dominant language. Thus, going by the 1974-2002 language policy, whichever way one interpreted what constituted the 'language of the locality' in Accra (and many other urban centres in Ghana), many children will be deprived of the benefits of mother tongue education the policy sought to provide.

Another sociolinguistic reality that the 1974-2002 policy could not address adequately is the complex sociolinguistic phenomenon (typically among urban populations) of Ghanaian children growing up in Ghana with English rather than an indigenous Ghanaian language as L1. Usually, such children are products of cross-ethnic marriages where couples do not speak each other's L1, especially among educated Ghanaians (Ansah 
and Mensa, 2005). It is important to emphasize, however, that this phenomenon is not widespread: possibly even non-existent in rural Ghana. To such people, the 2002 language- in- education policy was a proactive measure by the government to solve the problems inherent in the previous policy.

Nevertheless, even the 2002 policy could not solve the problems associated with language -in- education policy in Ghana. For instance, for the rural child or a child growing up in a relatively linguistically homogeneous community, the 2002 policy meant discouraging the use of the child's mother tongue, dominant language or even the only (well) known language. However, as Cummins (2000) asserts, discouraging the use of the mother tongue may stagnate the child's development of that language and consequently undermine the development of personal and conceptual foundations for learning. The current policy (2007) seems to have taken several of these factors into consideration in making room for the use of English or a Ghanaian language (where possible) as the medium of instruction in primary education.

Another thing the current policy does is that it includes pre-schoolers in the policy, something none of the previous policies did. As it stands, the current policy allows more opportunity for children to be taught in their L1 whichever that is. In other words, children who speak English as L1 get to be taught in English right from the pre-school stage (four years old). On the other hand, children who speak Ghanaian languages as L1 may get to be taught in their L1s, and also get to be familiar with the English language long before (from 4-9 years old) it becomes the sole medium of instruction in the classroom. However, one problem remains; the policy still emphasizes the use of the dominant Ghanaian language of a particular area, possibly discriminating against children from minority language backgrounds.

\section{Conclusion}

In this article, I have presented a short account of the historical developments of the language -in- education policy in Ghana from 1925 to 2007. The account shows that language- in- education policies in Ghana have been in a flux since the British colonial rule, but particularly so since independence in 1957. I have argued that while this flux may have been caused in part by instability in government leadership, the flux may also be attributable to the fact that policy after policy has proved non- implementable, possibly because the theoretical assumptions underlying such policies were inadequate in addressing the language- in- education needs of highly complex multi-ethnic/multilingual populations. In other words, the policies appear not to have taken into consideration the sociolinguistic realities in multi-ethnic communities where people have created fluid multilingual identities, practical constraints notwithstanding.

For language in education policies to achieve the desired results in multilingual/multiethnic communities such as Ghana, they should be based on sound theoretical constructs (e.g. perspectives from multicultural education; Banks, 2008) that take the sociolinguistic realities of such communities into account and see multi-ethnic/multilingual societies as pluralistic. For as Cummins (2000, p.1) has suggested, language- in- education policies in such communities ought to be based on dialogues that are informed by both insider and outsider (teachers, researchers and policy makers respectively) perspectives as both perspectives are important to the articulation of understandings. 
In Ghana, a greater collaboration between the Ministry of Education (the policy maker), the Ghana Education Service (the policy implementer), the Ghana Statistical Service and the Linguistics Association of Ghana (researchers) may be valuable not only in the formulation of implementable policies but also in the successful implementation of such policies. For example, given the level of linguistic diversity and the country's economic circumstances, teaching every child in its own mother tongue may appear very unrealistic. Even then, it is possible to offer a mother tongue education through decentralized language planning that is based on a theoretically sound national policy as has been done in Ethiopia, a much poorer country (Skutnabb-Kangas and Heugh 2012).

In this regard, demographic information from the Ghana Statistical services may be useful; for instance, in ensuring that the selection of a mother tongue for each decentralized area is a reflection of the actual sociolinguistic situation on the ground - that the pupils are, at least, familiar enough with the chosen language to receive instruction in it. In addition, the Ministry of Education and the Ghana Education Service could work together with teacher training institutions across the country to ensure that primary school teachers are trained and equipped to teach in the mother tongue or community languages of the schools they are posted to teach if the current language -in -education policy is to work.

\section{Endnote}

${ }^{a}$ Ethnologue assumes that because languages are fluid all numbers are estimates.

\section{Competing interests}

The author declares that she has no competing interest.

Received: 13 February 2014 Accepted: 13 June 2014

Published: 9 July 2014

\section{References}

Agbedor, PK. 1994. Language Planning for National Development: The Case of Ghana (Unpublished PhD Thesis). British Columbia, Canada: University of Victoria.

Ameyaw-Akumfi, C. 2002. English only: No more vernacular. Published in the 17th May 2002 edition of The Daily Graphic. http://www.ghanaweb.com/GhanaHomePage/NewsArchive/artikel.php?ID=24149 (accessed on 31/08/ 2009).

Andoh-Kumi, K. 1999. IEQ Ghana - Qualitative Research from University/Ministry Partnership: Informing School Language Policy Decisions. San Antonio, Texas: A paper presented at the annual conference of the Comparative International Education Society.

Ansah, GN, and PA Mensa. 2005. English Language and the job Market: A Sociolinguistic Study of Language Shift in Ghana, A paper presented at the 3rd Faculty of Arts Annual Conference. Legon: Faculty of Arts, University of Ghana.

Assembly of the African Union. 2006. Sixth Ordinary Session.asembly/AU/Dec.98(VI); (Doc.EX.CL/223 (VIII). http://www.au int/en/content/khartoum-23-january-24-january-2006-assembly-african-union-sixth-ordinary-session (accessed on 12/03/2010).

Baker, C. 2000. A parents' and teachers' Guide to Bilingualism, 2nd ed. Clevedon, England: Multilingual Matters.

Bamgbose, A. 2000. Language and Exclusion. Piscataway, New Jersey: Transaction Publishers.

Banks, J. 2008. An Introduction to Multicultural Education, 4th ed. Boston: Pearson, Allyn/Bacon.

Bantu Education Act, South Africa. 1957. http://www.bbc.co.uk/learningzone/clips/bantu-education-act-south-africa1957/6213.html.

BBC News. 2000. Africa media watch. http://news.bbc.co.uk/2/hi/africa/969508.stm (accessed on 14/03/2010).

Blommaert, J. 1996. The Politics of Multilingualism and Language Planning. Antwerp: Antwerp Papers in Linguistics 87.

Blommaert, J. 1999. Language Ideological Debates. Berlin and New York: Mouton de Gruyter.

Cummins, J. 2000. Language, Power, and Pedagogy: Bilingual Children in the Crossfire. Clevedon: Multilingual Matters.

Freeland, J. 2003. Intercultural-bilingual education for an interethnic-plurilingual society? The Case of Nicaragua. Comparative Education 39(2): 239-260.

Ghana Statistical Services. 2002. 2000 Population and Housing Census Summary Report, 22-23. Accra: Ghana Statistical Service.

Hemphill, RJ. 1974. Language use and Language Teaching in the Primary Schools of Kenya. In Language in Kenya, ed. WH Whiteley, 445-479. Oxford: Oxford University Press.

Heugh, KA, and P Pluddeman. 1995. Multilingual Education for South Africa. Johannesburg: Heinemann

Jespersen, O. 1922. Language: Its Nature, Development and Origin. George Allen and Unwin. 
Le Page, RB, and A Tabouret-Keller. 1985. Acts of Identity: Creole-Based Approaches to Language and Ethnicity. Cambridge: Cambridge University Press.

Lewis, MP. 2009. Ethnologue: Languages of the World, 16th ed. http://www.ethnologue.com. (accessed on 4/10/2010). Ministry of Education Science and Sports. 2007. Teaching syllabuses for English language (Primary 1-4). http://www.ges. gov.gh/PRIMARYSYLLABUS/ENGLISH\%20PRIMARY\%201-3.pdf. (accessed on 4/10/2010).

Mühlhäsler, P. 1996. Linguistic Ecology: Language Change and Linguistic Imperialism in the Pacific. London: Routledge National Education Policy Act (act no. 27 of 1996). Admission Policy for Ordinary Public Schools. http://www.education. gov.za/LinkClick.aspx?fileticket=WTGXHzBEbiQ=.

Obeng, SG. 1997. An analysis of the linguistic situation in Ghana. African Languages and Cultures 10(1): 63-81.

Owu-Ewie, C. 2006. The Language Policy of Education in Ghana: A Critical Look at the English Only Language Policy of Education. In Selected Proceedings of the 35th Annual Conference on African Linguistics, ed. J Mugane et al., 76-85. Somerville, MA: Cascadilla Proceedings Project.

Pattanayak, DP. 1981. Multilingualism and Mother Tongue Education. Delhi: Oxford University Press.

Pattanayak, DP (ed.). 1990. Multilingualism in India. Clevedon: Multilingual Matters.

Rampton, B. 1995. Crossing: Language and Ethnicity among Adolescents. London/New York: Longman.

Sebba, M. 2000. What is 'mother Tongue? Some Problems Posed by London Jamaican. In Language Blacks and Gypsies: Languages without a Written Tradition and Their Role in Education, ed. T Acton and M Dalphinis. London: Whiting and Birch.

Skutnabb-Kangas, T. 1981. Bilingualism or not: The Education of Minorities. Clevedon: Multilingual Matters.

Skutnabb-Kangas, T. 2000. Linguistic Genocide in Education-or Worldwide Diversity and Human Rights? Mahwah, NJ: Lawrence Erlbaum Associates.

Skutnabb-Kangas, T, and K Heugh (eds.). 2012. Multilingual Education and Sustainable Diversity Work: From Periphery to Center. New York: Routledge.

doi:10.1186/s13616-014-0012-3

Cite this article as: Ansah: Re-examining the fluctuations in language in-education policies in post-independence Ghana. Multilingual Education 2014 4:12.

\section{Submit your manuscript to a SpringerOpen ${ }^{\circ}$ journal and benefit from:}

- Convenient online submission

Rigorous peer review

- Immediate publication on acceptance

- Open access: articles freely available online

- High visibility within the field

Retaining the copyright to your article

Submit your next manuscript at $\boldsymbol{\sim}$ springeropen.com 